\title{
Determination of the Normal Fluid Load on Inclined Cylinders from Optical Measurements of the Reconfiguration of Flexible Filaments in Flow
} DOI:

10.1016/j.jfluidstructs.2017.10.009

\section{Document Version \\ Accepted author manuscript}

Link to publication record in Manchester Research Explorer

Citation for published version (APA):

Silva Leon, J., Cioncolini, A., \& Filippone, A. (2018). Determination of the Normal Fluid Load on Inclined Cylinders from Optical Measurements of the Reconfiguration of Flexible Filaments in Flow. JOURNAL OF FLUIDS AND STRUCTURES, 76, 488-505. https://doi.org/10.1016/j.jfluidstructs.2017.10.009

Published in:

JOURNAL OF FLUIDS AND STRUCTURES

\section{Citing this paper}

Please note that where the full-text provided on Manchester Research Explorer is the Author Accepted Manuscript or Proof version this may differ from the final Published version. If citing, it is advised that you check and use the publisher's definitive version.

\section{General rights}

Copyright and moral rights for the publications made accessible in the Research Explorer are retained by the authors and/or other copyright owners and it is a condition of accessing publications that users recognise and abide by the legal requirements associated with these rights.

\section{Takedown policy}

If you believe that this document breaches copyright please refer to the University of Manchester's Takedown Procedures [http://man.ac.uk/04Y6Bo] or contact uml.scholarlycommunications@manchester.ac.uk providing relevant details, so we can investigate your claim.

\section{OPEN ACCESS}




\title{
Determination of the Normal Fluid Load on Inclined Cylinders from Optical Measurements of the Reconfiguration of Flexible Filaments in Flow
}

\author{
Jorge Silva-Leon ${ }^{\mathrm{a}, \mathrm{b}}$, Andrea Cioncolini $^{\mathrm{a}}$, Antonio Filippone ${ }^{\mathrm{a}}$ \\ a School of Mechanical, Aerospace and Civil Engineering, University of Manchester, George Begg Building, Sackville Street, \\ M13 9PL, Manchester, United Kingdom \\ b Escuela Superior Politécnica del Litoral, ESPOL, Facultad de Ingeniería en Mecánica y Ciencias de la Producción, \\ Campus Gustavo Galindo Km 30.5 Vía Perimetral, P.O. Box 09-01-5863, Guayaquil, Ecuador
}

\begin{abstract}
Reconfigured flexible filaments exposed to steady fluid load were investigated using a novel non-contact optical technique to measure the normal fluid force due to the fluid loading on inclined cylinders for Reynolds numbers from 25 to 460: a range not covered in previous studies that is of relevance in drag reduction and energy harvesting applications. The ranges of the buoyancy number and the Cauchy number covered in the tests were $3.6 \times 10^{4} \leq B \leq 2.1 \times 10^{6}$ and $7.6 \times 10^{4} \leq C a \leq 1.4 \times 10^{7}$. These newly generated data were then used to assess and extend the validity of existing prediction methods for the normal fluid force at low Reynolds numbers. New prediction methods for the equilibrium inclination angle and for the fluid dynamics load were developed for small Reynolds number applications, based on extrapolating existing theoretical results for marine vegetation.
\end{abstract}

Key words: normal fluid force, inclined cylinders, flexible filaments, reconfigured structure.

\section{Introduction}

The determination of the steady fluid dynamics loads on slender and stationary cylindrical bodies is a problem relevant to several practical applications, and has been the subject of extensive research for the last century. Slender cylindrical cables and stranded wires are encountered in electrical power transmission systems and telecommunication lines and are extensively used for structural support in aerial applications such as architectural structures and suspension bridges (Hoang et al., 2015). The knowledge of the steady fluid forces is required in the design of offshore slender structures (Ersdal and Faltinsen, 2006), and slender bodies subjected to steady fluid loads are common in natural systems, notably in the reconfiguration of vegetation (de Langre, 2008; Luhar and Nepf, 2011). Recently, the study of thin and flexible cylindrical filaments in relative motion with respect to the surrounding fluid has become an active area of research due to 
potential use of flexible filaments for drag reduction (Favier et al., 2009; Niu and $\mathrm{Hu}, 2011$ ) and energy harvesting (Grouthier et al., 2014). In all these applications, stationary and slender cylindrical structures are exposed to a steady fluid flow with arbitrary relative inclination between the flow direction and the cylindrical structure axis, covering all possible inclinations from cross-flow (i.e. flow direction orthogonal to the axis of the cylindrical structure) to parallel flow (i.e. flow direction aligned with the axis of the cylindrical structure). It is evident that the force exerted by the flow on the stationary cylindrical structure is a key design parameter, together with its dependence on the relative inclination between the flow direction and the axis of the cylindrical structure.

Available data of fluid forces on stationary inclined cylinders (Relf and Powell, 1917; Bursnall and Loftin, 1951; Smith et al., 1972; Ersdal and Faltinsen, 2006) have been generated for naval and wind engineering applications, where the Reynolds number (based on the cylindrical structure diameter and the free stream flow velocity) typically varies between $\operatorname{Re} \approx 10^{3}$ and $\operatorname{Re} \approx 10^{6}$. Reynolds number values typical of stationary flexible filaments of interest for drag reduction and energy harvesting applications, on the other hand, are in the range of $\operatorname{Re} \approx 10$ to $\mathrm{Re} \approx 10^{3}$ : well below the range covered by existing data and prediction methods. The main objective of the present study is therefore to provide new data on the fluid dynamics load on stationary and slender cylindrical structures for these low Reynolds number applications. In particular, using very thin and flexible filaments and a novel non-invasive optical technique we indirectly resolved the very small fluid dynamics loads (on the order of 10-100 $\mu \mathrm{N}$ ) for relative inclinations between flow direction and filament axis from 10 to 80 degrees and Reynolds numbers from $R e=25$ to $R e=460$, thus significantly extending the range covered to date. These newly generated data were then used to assess the validity of existing fluid dynamics load prediction methods for inclined cylinders at low Reynolds number values. Finally, new prediction methods for the fluid dynamics load and the inclination angle are developed for small Reynolds number applications.

In what follows, the experimental technique is presented first, followed by the description and discussion of the results.

\section{Experiments and Methods}

The experimental technique devised here to indirectly measure the fluid dynamics load on inclined stationary cylinders is based on the static reconfiguration of flexible thin filaments exposed to steady airflow in a wind tunnel. A schematic 
representation of the test piece is provided in Fig. 1. The test piece was realized by introducing the flexible filament extremity for about $5 \mathrm{~mm}$ into a straight stainless steel support tube (external diameter: $1.1 \mathrm{~mm}$, internal diameter $0.9 \mathrm{~mm}$, length: $100 \mathrm{~mm}$ ). The filament extremity was then fixed with glue cement to the free end of the support tube so as to reproduce a cantilever boundary condition for the flexible filament. The homogeneity of the connection of the filament to the support tube was checked by rotating the support tube around its axis while holding it horizontally, and visually verifying that the configuration assumed by the inflection of the hanging filament remained the same regardless of the rotation position of the support. The support tube was secured to a support plate and was introduced from the top inside the wind tunnel so that in the absence of flow the filament would hang vertically like a pendulum in cross flow.

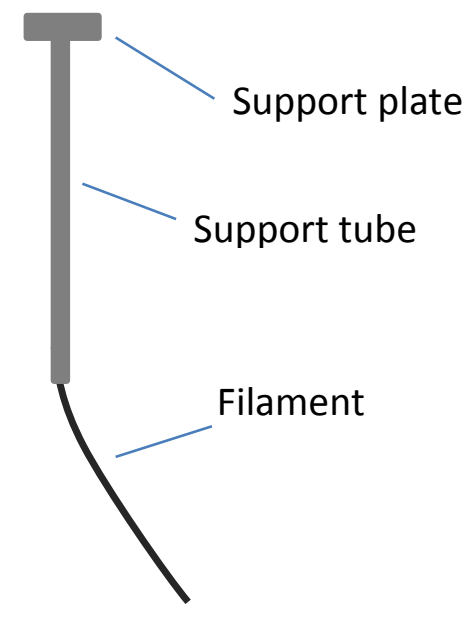

Fig. 1 Schematic representation of the test piece.

Under the influence of a steady fluid load, as shown in Fig. 2, the flexible filament is deflected into a static equilibrium configuration with inclination with respect to the vertical depending on the wind speed, similarly to what is observed with plants and other slender flexible structures exposed to steady fluid flow (Luhar and Nepf, 2011; Schouveiler et al., 2005). As can be noticed in Fig. 2, due to its high flexibility the reconfigured filament is bent only in a very small region close to the support tube, while it remains straight and rectilinear over most of its length. 


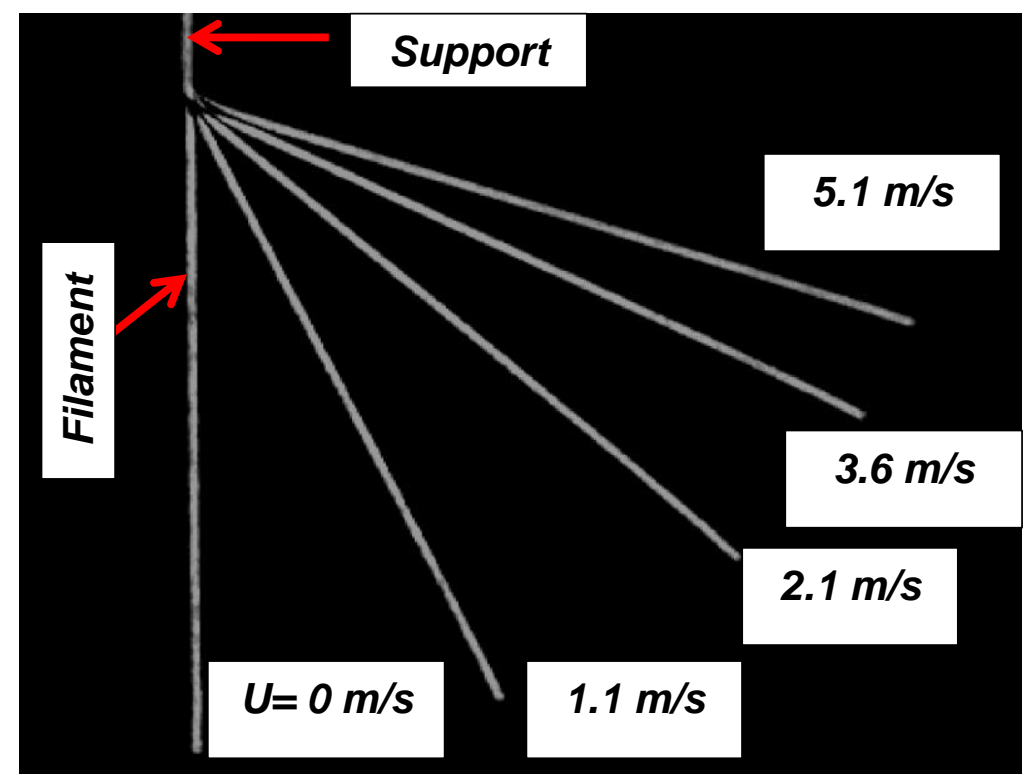

Fig. 2 Static equilibrium configurations of the flexible filament (filament No. 3 from Table 1) as the wind speed is gradually increased from $0 \mathrm{~m} / \mathrm{s}$ (no flow) to $5.1 \mathrm{~m} / \mathrm{s}$ (the flow is horizontal from left to right).

Clearly, the static reconfiguration of the filament under a steady wind speed is determined by the equilibrium of all the forces acting on the filament, namely its own weight, the fluid load and the reaction of the support tube. This latter, in particular, includes a concentrated bending moment that accounts for the filament bend close to the fixed end. As the reconfigured filament is rectilinear except near the fixed end, no other bending effects are present besides the concentrated bending moment at the fixed end. A simple momentum balance with respect to the filament fixed extreme, therefore, can in principle provide the total normal force exerted by the flow on the filament, provided that the total filament weight and the concentrated bending moment at the filament fixed extreme are known. The absence of any appreciable variation of the inclination angle of the reconfigured filament along its length allows deducing the local normal force at the filament equilibrium inclination from the total normal force exerted by the flow on the filament. In particular, the reconfigured filament in equilibrium can be modeled as schematically indicated in Fig. 3, where $W$ represents the filament weight, $F$ the fluid force while $M_{\text {spring }}$ is the concentrated bending moment that accounts for the filament bend close to the fixed end. As can be seen in Fig. 3, both $W$ and $F$ are decomposed into their normal $\left(W_{N}\right.$ and $\left.F_{N}\right)$ and tangential $\left(W_{T}\right.$ and $\left.F_{T}\right)$ components with respect to the filament axis. 


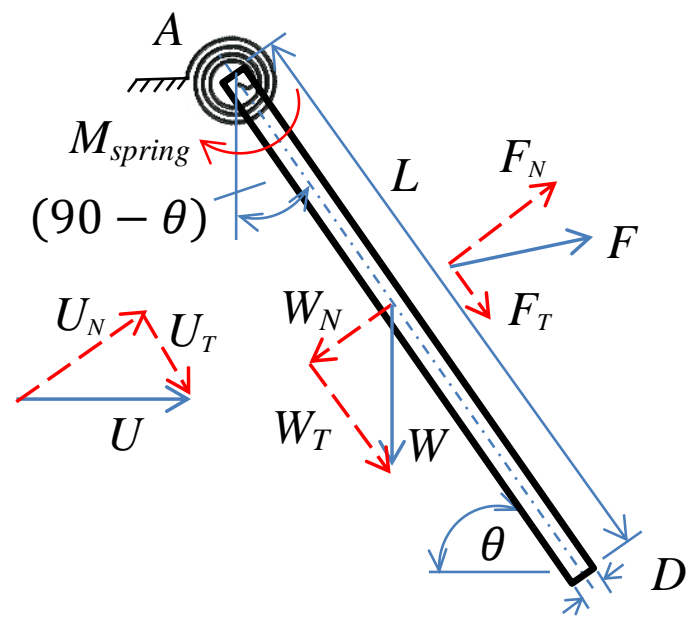

Fig. 3 Schematic model of the reconfigured filament in equilibrium.

The free stream flow velocity is $U$, which in Fig. 3 is decomposed into its normal $\left(U_{N}\right)$ and tangential $\left(U_{T}\right)$ components with respect to the filament axis. A momentum balance with respect to the filament fixed extreme (point A in Fig. 3) yields:

$$
F_{N}=W_{N}+2 M_{\text {spring }} / L
$$

where $L$ is the effective rectilinear length of the filament, which is determined from image processing of the reconfigured filament as schematically shown in Fig. 4.

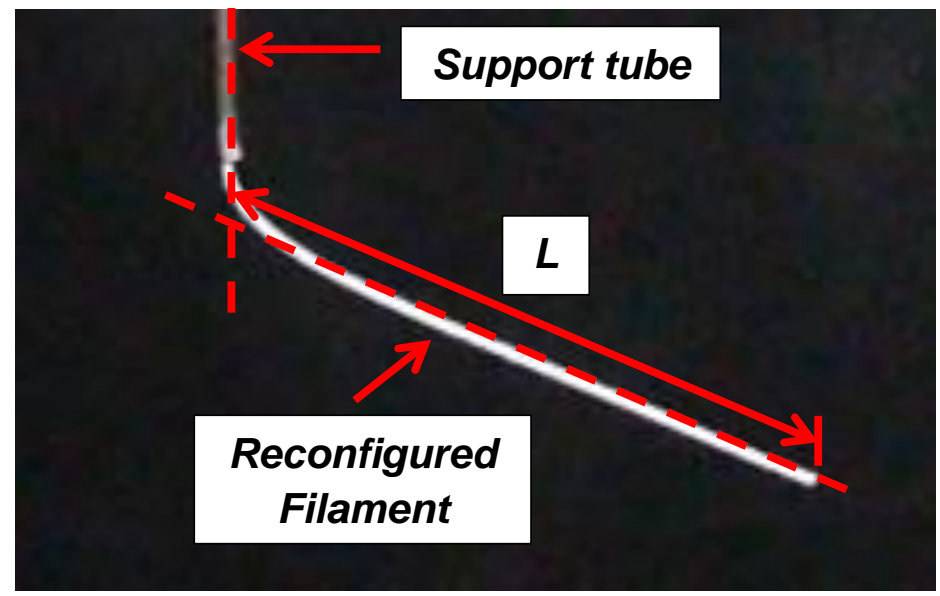

Fig. 4 Determination of the effective rectilinear length $L$ of the reconfigured filament (Filament No. 1 from Table 1, $U=4.2 \mathrm{~m} / \mathrm{s}$ ).

As can be noticed in Fig. 4, the effective rectilinear length $L$ of the reconfigured filament is slightly shorter than the filament nominal length. In this study, due to the high flexibility and the relatively large length to diameter ratio of the filaments used, 
the effective rectilinear length $L$ of the filaments was always only a few percent shorter than the nominal length, a difference that within the limits of the present study was considered of second order importance. The normal component of the filament weight is given as:

$$
W_{N}=\left(\rho_{s}-\rho_{f}\right) g(\pi / 4) D_{a v g}^{2} L \cos \theta
$$

where $\rho_{s}$ and $\rho_{f}$ are the filament and fluid (air) densities, $D_{\text {avg }}$ is the average diameter of the filament, $g$ is the acceleration of gravity and $\theta$ is the inclination angle of the filament with respect to the horizontal. The concentrated bending moment $M_{\text {spring }}$ is estimated as follows:

$$
M_{\text {spring }}=\kappa(90-\theta)
$$

where $k$ is the flexural elastic constant of the filament, which was measured in static deflection tests under self-weight (more details in Appendix A). In this study, due to the high flexibility of the filaments used, the contribution of the concentrated bending moment to the force in the second term on the right-hand side of Eq. (1) was always at least three orders of magnitude smaller than the normal component of the filament weight $W_{N}$. Besides, the filament density was much larger than the air density (i.e. $\rho_{s}>>\rho_{f}$ ). For the experiments presented here, therefore, Eq. (1) can be simplified as follows:

$$
F_{N} \approx W_{N}=\rho_{S} g \frac{\pi}{4} D_{a v g}^{2} L \cos \theta
$$

As can be seen in Eq. (4), the only parameters that have to be measured are the fluid flow speed and the inclination of the filament with respect to the vertical. This latter, in particular, can conveniently be deduced with non-contact image capture and post processing. This provides an indirect measuring technique for the normal fluid force on inclined cylinders based on non-invasive optical measurements of the deflection of highly flexible filaments in steady fluid flow. This indirect technique allows circumventing the difficulty of directly measuring the very small fluid forces that are at play at the low Reynolds numbers of interest here, which are on the order of $10-100 \mu \mathrm{N}$. An intrinsic limitation of this technique is that the fluid flow velocity and the filament equilibrium inclination vary simultaneously, so that it is not possible to run experiments keeping a fixed inclination while varying the flow velocity, or vice-versa vary the filament inclination while keeping the same flow velocity. The parameter space can however be explored by systematically varying the filament diameter and length. In this study, in particular, we tested nine flexible filaments with average diameter $D_{\text {avg }}$ in the range of $400 \mu \mathrm{m}$ to $610 \mu \mathrm{m}$ and 
nominal length $L_{\text {nom }}$ from $25 \mathrm{~mm}$ to $75 \mathrm{~mm}$ (measured to within $\pm 0.5 \mathrm{~mm}$ ), as summarized in Table 1. Another limitation of the present experimental technique is that the fluid force has to be large enough to deflect the filament, and this constitutes a lower limit on the achievable Reynolds number that depends on the density difference between filament and fluid, which in turn determines the filament net weight.

Table 1. Geometry of the flexible filaments tested

\begin{tabular}{lccccccccc}
\hline Filament No. & 1 & 2 & 3 & 4 & 5 & 6 & 7 & 8 & 9 \\
\hline $\boldsymbol{L}_{\text {nom }}(\mathbf{m m})$ & 25.0 & 50.0 & 75.0 & 25.0 & 50.0 & 75.0 & 25.0 & 50.0 & 73.5 \\
$\boldsymbol{D}_{\max }(\mathbf{m m})$ & 0.40 & 0.40 & 0.40 & 0.66 & 0.66 & 0.66 & 0.44 & 0.46 & 0.45 \\
$\boldsymbol{D}_{\min }(\mathbf{m m})$ & 0.40 & 0.40 & 0.40 & 0.56 & 0.56 & 0.56 & 0.38 & 0.40 & 0.39 \\
$\boldsymbol{D}_{\text {avg }}(\mathbf{m m})$ & 0.40 & 0.40 & 0.40 & 0.61 & 0.61 & 0.61 & 0.41 & 0.43 & 0.42 \\
$\boldsymbol{L}_{\text {nom }} / \boldsymbol{D}_{\text {avg }}$ & 63 & 125 & 188 & 41 & 82 & 123 & 61 & 116 & 175 \\
\hline
\end{tabular}

The flexible filaments in Table 1 were realized using an additive manufacturing system (3D-Bioplotter by Envisiontec GMBH, Germany) that allowed producing thin and straight filaments with the desired flexibility and smooth surface finishing, as shown in Fig. 5. The manufacturing process was a low-temperature extrusion via nozzles of $0.41,0.61$ and $0.84 \mathrm{~mm}$ ID which were used to produce filaments of $0.45 \mathrm{~mm}$ (extrusion pressure of $0.15 \mathrm{MPa}$ and $1 \mathrm{~mm} / \mathrm{s}$ deposition speed), $0.40 \mathrm{~mm}$ (extrusion pressure of $0.5 \mathrm{MPa}$ and $4.4 \mathrm{~mm} / \mathrm{s}$ deposition speed) and $0.66 \mathrm{~mm}$ (extrusion pressure of $0.6 \mathrm{MPa}$ and $0.6 \mathrm{~mm} / \mathrm{s}$ deposition speed) in diameter. All other processing parameters, namely extrusion temperature $\left(27^{\circ} \mathrm{C}\right)$, and nozzle offset from platform $(0.5 \mathrm{~mm})$ were kept constant throughout the process.
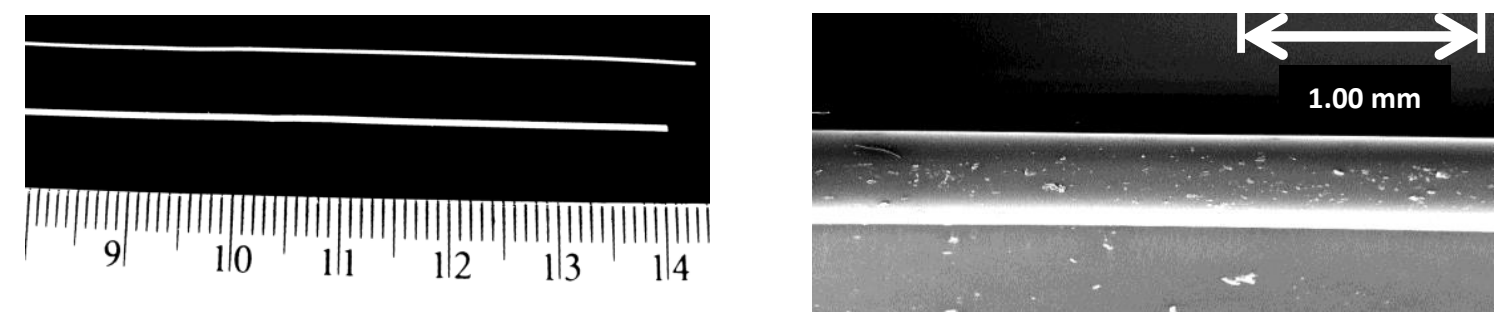

Fig. 5 Flexible filaments alongside a ruler with scale in centimeters (left), and SEM image detail of the filament surface finishing (right).

In particular, the filaments were manufactured from a highly flexible commercial silicone rubber $\left(\rho_{s}=1.00 \pm 0.05 \mathrm{~g} / \mathrm{cm}^{3}\right)$ and were printed following straight paths in order to avoid any bends or permanent deformations. The filaments diameter was measured optically at several locations along the filaments (to within $\pm 20 \mu \mathrm{m}$ ). 
Maximum $D_{\max }$ and minimum $D_{\min }$ diameter values are included in Table 1, together with the average figures. As can be seen, the variation of the diameter along the filaments is either negligible (filaments 1-3) or within a few percent (filaments 4-9). These variations of the filaments diameter were considered of second order importance and were therefore neglected in the post-processing of the data, where only the average figures were used. Additionally, the tensile modulus $(E)$, Poisson ratio $(v)$ and bending rigidity $(E I)$ of the filaments were determined in preliminary tension and static deflection tests (details and results are included in Appendix A). Even though these parameters are not used in the analysis presented here, they are included for completeness and for future reference, notably for numerical modeling.

The experiments were performed in a commercial wind tunnel (Armfield) of octagonal cross section with height and width of $350 \mathrm{~mm}$. Flow speed measurements were performed with a calibrated hot-wire anemometer which was validated in-situ via a standard experiment of vortex shedding from a circular cylinder in cross flow (see Appendix B for details). In particular, the hot-wire anemometer was located $200 \mathrm{~mm}$ downstream and $100 \mathrm{~mm}$ below the lowest point of the hanging filament in order to obtain undisturbed flow velocity measurements. The extension of the boundary layer, the uniformity of the velocity profile and the turbulence intensity within the wind tunnel were measured before testing the flexible filaments. The boundary layer extended less than $10 \mathrm{~mm}$ from the walls of the wind tunnel at a flow velocity of $1.0 \mathrm{~m} / \mathrm{s}$ corresponding to the lowest speed setting employed for this experiment, and the velocity profile across the wind tunnel (excluding the boundary layer) was uniform to within 1\% (i.e. less than $1 \%$ deviation of the normalized speed with respect to the centerline speed). This assures that the flexible filaments were always exposed to a uniform and fully developed velocity profile during the tests. The turbulence intensity was $0.6 \%$ in the range of free stream velocities of $1 \mathrm{~m} / \mathrm{s}$ to $10 \mathrm{~m} / \mathrm{s}$ of interest here. Finally, the temperature and pressure in the laboratory during the experiments were $293 \pm 1 \mathrm{~K}$ and $101 \pm 1 \mathrm{kPa}$, respectively.

The reconfiguration of the flexible filaments was recorded using a digital camera (Lumix DMC-FZ200 by Panasonic; recording frequency: 200 frames per second; acquisition duration: $60 \mathrm{~s}$; resolution $480 \times 640$ pixels) positioned on the side of the wind tunnel ( $X-Y$ plane), as schematically shown in Fig. 6. The equilibrium inclination angle of the reconfigured filaments was deduced via standard image processing of the recorded videos. In principle, one image would suffice to determine the inclination angle of the filament. In practice, however, the use of fast 
video imaging and rather long acquisition time allows one to check for possible filament vibrations and movement during the tests. None of these was observed during the experiments, so that all the results presented here refer to static reconfigured filaments in steady fluid flow. Occasional flow fluctuations induced very small oscillations on the filament, but these decayed shortly after. In fact, the root-mean-squared displacement in the $Z$ direction was in the worst case $0.19 \mathrm{~mm}$, i.e. below the optical resolution in this plane which was of $0.22 \mathrm{~mm}$.

a)
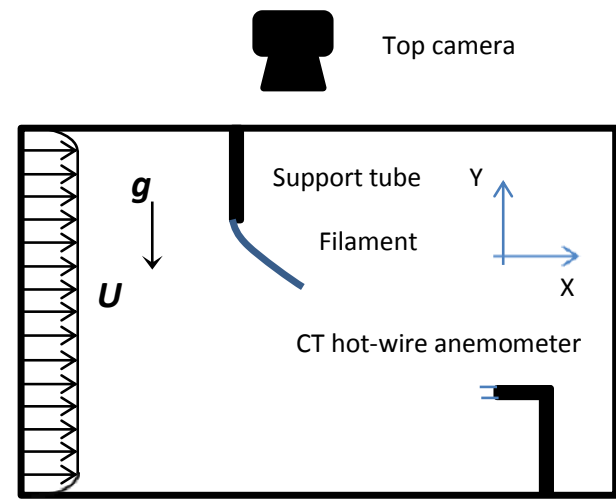

b)

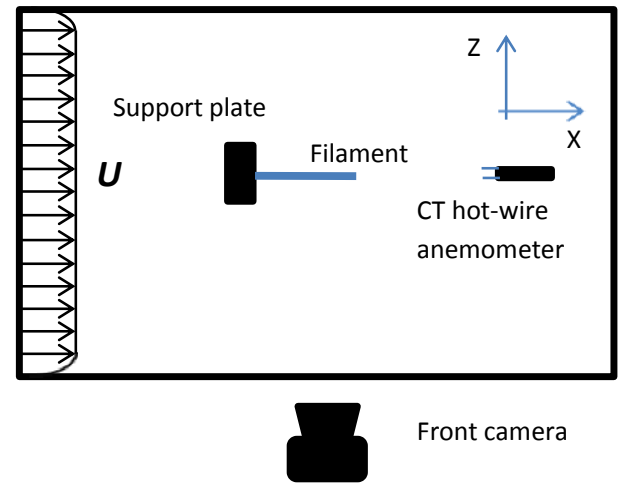

Fig 6 Schematic representation of the experimental setup: a) front view, plane $X-Y$; b) top view, plane $X-Z$.

As schematically shown in Fig 6, an additional fast imaging camera was located on the top of the wind tunnel to check for any filament lateral deflections in the $X-Z$ plane, which would indicate a possible imperfection in the setup. The filaments in static equilibrium did not exhibit resolvable lateral deflections in the $X-Z$ plane during any of the tests we performed. The root-mean-squared displacement in the $Z$ direction was at most $0.14 \mathrm{~mm}$, i.e. below the optical resolution in this plane which was of $0.15 \mathrm{~mm}$. The tests on the flexible filaments began with the filament hanging vertically from the ceiling of the wind tunnel $\left(\theta=90^{\circ}\right)$ and no flow. The wind tunnel fan motor was then started and the wind velocity was slowly set to 1.0 $\mathrm{m} / \mathrm{s}$ (minimum stable velocity achievable in this wind tunnel). In order to avoid any 
transients the video recording started about 15 seconds after setting the wind speed, a delay sufficient to damp out any transient effects (the fluid transit time through the wind tunnel was below 3-4 s). The wind speed was then gradually increased in steps of roughly $0.5 \mathrm{~m} / \mathrm{s}$ until just before the filament started to vibrate. The flow speed was then decreased gradually down to the minimum. No hysteresis effects were observed during the tests. This procedure was repeated for each of the filaments listed in Table 1. Moreover, each data point was repeated three times after rotating the filament support tube of about 90 degrees around its axis, therefore collocating the filament facing the flow in three different orientations. This allowed us to check the influence of any cross section out-of-roundness and/or any sensitivity to coupling imperfections of the filament to the support tube. No noticeable effects were observed during the tests. Notwithstanding the filaments flexibility, no elongation and/or permanent deformation were observed during or after the tests.

\section{Results and discussion}

Representative results obtained for filaments No. 1 to No. 3 from Table 1 are presented in Fig. 7. Analogous results for the other filaments tested are provided in Appendix C. In particular, the data presented in Fig. 7 include the filament inclination angle with respect to the horizontal, the normal force calculated from Eq. (4) and the normal force per unit filament length, all presented as function of the flow velocity. As can be seen, the filament inclination angle presents a decreasing trend versus flow velocity, consistently indicating that the filament inclination with respect to the horizontal gradually decreases as the flow velocity is increased. The normal force depicts a growing and saturating trend with a clear dependence on the filament length, i.e. longer filaments experience larger normal forces. In particular, the normal force tends asymptotically to the total filament weight (included in Fig. 7 as horizontal dashed lines) for large flow velocities, where the filament reconfigures to a close-to-horizontal configuration. Normal forces per unit filament length only depend on the flow velocity, as can be seen in Fig. 7 (bottom). This can be justified by considering that within the limits of the present approach the normal force per unit filament length depends on the filament diameter and inclination angle, as shown in Eq. (4). The diameter is the same for the filaments in Fig. 7, while the inclination angle is in a one-to-one correspondence with the flow velocity, as shown in Fig. 7 (top). 

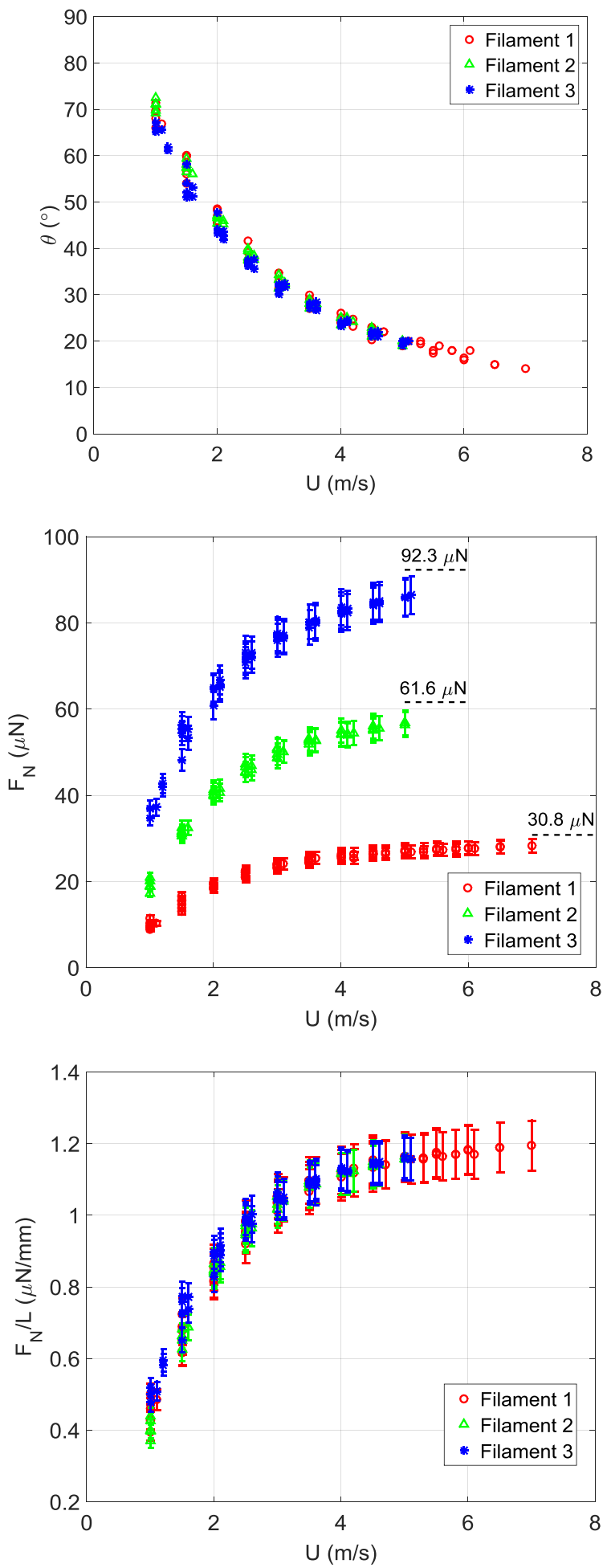

Fig. 7 Results for filaments 1 through 3 from Table 1: Inclination angle vs. flow velocity (top); normal fluid force vs. flow velocity (middle); and specific normal fluid force per unit filament length vs. flow velocity (bottom). 
Notably, the data presented in Fig. 7 include all the measurements taken with filaments No. 1 to No. 3, namely the measurements taken with both increasing and decreasing wind speeds, as well as the repeated data points generated after rotating the filament support tube around its axis.

Moving on, we now compare our newly generated data for the normal force on inclined cylinders at low Reynolds number with existing data and prediction methods, generated and developed for high Reynolds number applications (above about $\mathrm{Re}=2000$ ). A popular prediction method for ocean engineering applications is provided by the so-called loading function (Casarella and Parsons, 1970). In this approach, the normal force $F_{N}$ is predicted as:

$$
F_{N}=F_{\perp} f(\theta)
$$

where $f(\theta)$ is the loading function: a dimensionless function of the inclination angle $\theta$ determined empirically to fit measured data, while $F_{\perp}$ is the normal force acting on the same cylinder in cross flow configuration:

$$
F_{\perp}=C_{d} \frac{1}{2} \rho_{f} U^{2} D L
$$

where the drag coefficient $C_{d}$ is calculated using the free-stream flow Reynolds number:

$$
R e=\rho_{f} U D / \mu_{f}
$$

where $D$ and $L$ are the cylinder diameter and length, while $\rho_{f}$ and $\mu_{f}$ are the fluid density and viscosity. As can be seen, the basic idea of the loading function approach is to predict the normal fluid force acting on an inclined cylinder by correcting the normal force that would act on the same cylinder exposed to the same flow but in cross-flow configuration (i.e. with the cylinder axis perpendicular to the flow velocity) by making use of an empirically derived loading function, which is a function of the cylinder inclination angle. The loading function approach has been developed for ocean engineering applications where the Reynolds number is typically on the order of $10^{3}-10^{5}$. Different loading functions have been proposed in the literature (Casarella and Parsons, 1970), however the simplest and most frequently used is the following:

$$
f(\theta)=\sin ^{2} \theta
$$

Another well-known prediction method for the normal force on inclined cylinders is the so-called independence or cross flow principle. In this method, the normal force $F_{N}$ is predicted as: 


$$
F_{N}=C_{d, N} \frac{1}{2} \rho_{f} U_{N}^{2} D L
$$

As can be seen, Eq. (9) is formally analogous to Eq. (6) for the normal force acting on a cylinder in cross-flow configuration. However, the free stream velocity $U$ in Eq. (6) is replaced in Eq. (9) with its normal component $U_{N}$, and the drag coefficient $C_{d, N}$ in Eq. (9) is evaluated at a Reynolds number computed with Eq. (7) using the normal velocity component $U_{N}$ in place of the free stream velocity $U$. In other words, the basic idea of the independence principle is to predict the normal fluid force acting on an inclined cylinder using the same relation that holds for the same cylinder in cross-flow configuration, by simply replacing the free stream flow velocity with its normal component to the cylinder axis. Presently, the theoretical proof of validity of the independence principle is limited to laminar flows with no flow separation, and assuming an infinite cylinder with no end-effects (Zdravkovich, 2003). Existing experimental evidence (Zdravkovich, 2003) suggests that the independence principle is applicable for cylinder inclination angles between $90^{\circ}$ and $50^{\circ}$, while its applicability for other inclination angles remains uncertain at the moment. On the other hand, loading functions are not restricted to any specific range of inclination angles and being wholly empirical can potentially accommodate all situations of practical interest.

It is evident from inspection of Eq. (6) and Eq. (9) that in order to use either the loading function or the independence principle to predict the normal fluid load on inclined cylinders, one needs a correlation for the drag coefficient $C_{d}$ versus Reynolds number for cylinders in cross flow. In the experiments discussed here the Reynolds number varies between 25 and 460, a range where the variation of the drag coefficient is large and cannot be ignored by simply assuming a constant drag coefficient as frequently done in high Reynolds number applications. The drag coefficient correlation specifically derived for use here reads as follows:

$$
C_{d}=\left(1.13+\frac{11.4}{R e^{0.808}}\right)^{0.952}, \quad \text { for } 10^{-1} \leq R e \leq 10^{5}
$$

In particular, Eq. (10) was derived using available data from the literature for Reynolds number from $10^{-1}$ to $10^{5}$ and is quite accurate in the range of interest here (more details are provided in Appendix D). The range of validity of Eq. (10) was selected to cover the Reynolds number values of interest here, as well as those covered by existing studies of relevance for the present work. Notably, Eq. (10) is not valid for the drag crisis, where a more complicated fitting equation would be required.

Our newly generated data for the normal force on inclined cylinders at low Reynolds number are presented in Fig. 8 as the ratio of the normal force on the inclined cylinder to the normal force generated on the same cylinder in cross flow configuration, i.e. $F_{N} / F_{\perp}$ (referred to in the following as normal force ratio) versus 
cylinder inclination. Literature data (Bursnall and Loftin, 1951; Ersdal and Faltinsen,

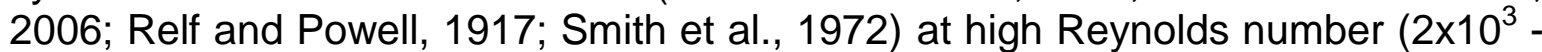
$3 \times 10^{5}$ ) are also included in Fig. 8, as well as the loading function in Eq. (8) (more details on these literature data for inclined cylinders are provided in Appendix E). The relative uncertainty in the normal force ratio $F_{N} / F_{\perp}$ for the present data is within $5-15 \%$ and is notably larger at higher inclination angles, which explains the higher scatter in the data that can be observed in Fig. 8 at high inclination angles. As can be seen, our data at low Reynolds number compare favourably with literature data generated at higher Reynolds number, and overall the data display a growing and saturating sigmoidal trend with inclination angle that is rather well reproduced by the loading function in Eq. (8). Despite its simplicity and within the limits of the present study, therefore, the loading function approach seems appropriate to predict the normal force on inclined cylinders even at low Reynolds number values. In particular, our newly generated data are predicted with a mean absolute error of $16.1 \%$.

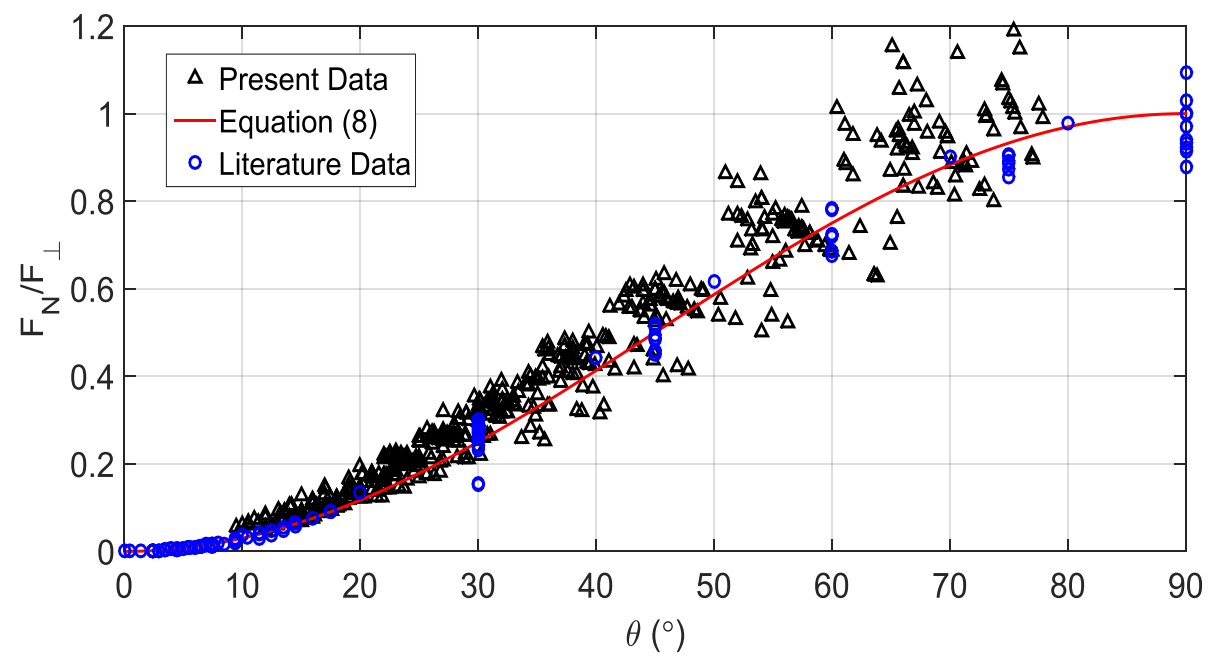

Fig. 8 Normal force ratio $F_{N} F_{\perp}$ vs. cylinder inclination angle.

Our newly generated data for the normal force on inclined cylinders at low Reynolds number are displayed in Fig. 9 as normal force per unit cylinder length versus the predictions of the independence principle in Eq. (9). Literature data (Bursnall and Loftin, 1951; Ersdal and Faltinsen, 2006; Relf and Powell, 1917; Smith et al., 1972) at high Reynolds number $\left(2 \times 10^{3}-3 \times 10^{5}\right)$ are also included in Fig. 9 (mean absolute percentage error of $17.1 \%$ ). As can be seen, our measurements and predictions compare quite well (mean absolute error of $11.4 \%$ ), indicating that within the limits of the present study the independence principle approach works well at low Reynolds numbers. Notably, this approach seems to work well at all inclination angles, not only for cylinder inclination angles between $90^{\circ}$ and $50^{\circ}$ where this method has been experimentally validated (Zdravkovich, 2003). 


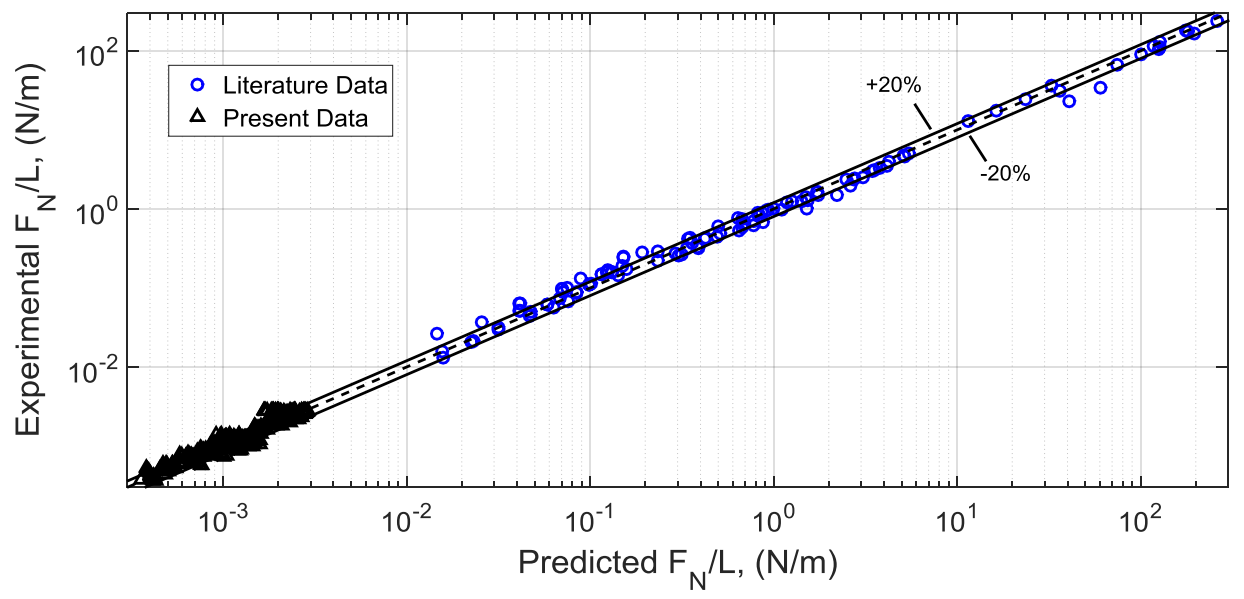

Fig. 9 Normal force per unit cylinder length: measurements vs. predictions of the independence principle in Eq. (9).

In the context of marine vegetation reconfiguration, (Luhar and Nepf, 2011) recently studied the deflections of flexible rectangular blades (vertical and positively-buoyant) due to steady water cross flow. Using the Euler-Bernoulli beam theory, they derived a theoretical model for the prediction of the blade equilibrium configuration under steady fluid load as function of two dimensionless parameters, namely the Cauchy $\mathrm{Ca}$ and buoyancy $B$ numbers, which they defined as follows:

$$
\begin{aligned}
& C a=\frac{1}{2} \frac{\rho_{f} C_{d} b U^{2} L^{3}}{E I} \\
& B=\frac{\left(\rho_{f}-\rho_{s}\right) g A L^{3}}{E I}
\end{aligned}
$$

where $b$ stands for the blade width projected to the flow, $L$ is the axial length of the blade, $A$ is the blade axial cross section, $C_{d}$ is the drag coefficient of the vertical blade in cross flow, $U$ is the free stream flow speed, $g$ is the acceleration of gravity, $E l$ is the bending rigidity of the blade, while $\rho_{f}$ and $\rho_{s}$ are the densities of the fluid and the blade, respectively. Particularly, our experimental data for the flexible filaments lie in the ranges of $3.6 \times 10^{4} \leq B \leq 2.1 \times 10^{6}$ and $7.6 \times 10^{4} \leq C a \leq 1.4 \times$ $10^{7}$. In their study, (Luhar and Nepf, 2011) considered also the limiting case of flexible blades with zero rigidity, i.e. highly flexible reconfiguring blades. The simplified relation they derived for the prediction of the blade equilibrium inclination angle for the limiting case of zero blade rigidity reads as follows:

$$
\sin \varphi=(C a / B) \cos ^{2} \varphi
$$

where $\varphi$ was the angle between the blade and the vertical $\left(\varphi=0^{\circ}\right.$ when the blade was upright with no deformation). Even though originally derived for rectangular 
blades, and not for filaments, Eq. (13) is specific for highly flexible reconfiguring structures, so that its applicability to the flexible filaments of interest here seems apt, at least as a first approximation. This extrapolation gives:

$$
\sin (90-\theta)=\frac{2}{\pi} C_{d} \frac{\rho_{f}}{\left(\rho_{s}-\rho_{f}\right)} \frac{U^{2}}{g D_{\text {avg }}} \cos ^{2}(90-\theta)
$$

As can be seen in Eq. (14), the ratio of the Cauchy to buoyancy numbers $C a / B$ can conveniently be expressed as the product of the drag coefficient $C_{d}$, the mass ratio $M^{*}=\rho_{f} /\left(\rho_{s}-\rho_{f}\right)$ and the Froude number $F r=U^{2} /\left(g D_{\text {avg }}\right)$, thus providing further insight. Measured inclination angles for the flexible filaments in Table 1 are compared with the predictions of Eq. (14) in Fig. 10. In particular, the drag coefficient $C_{d}$ needed as input to Eq. (14) was evaluated using Eq. (10).

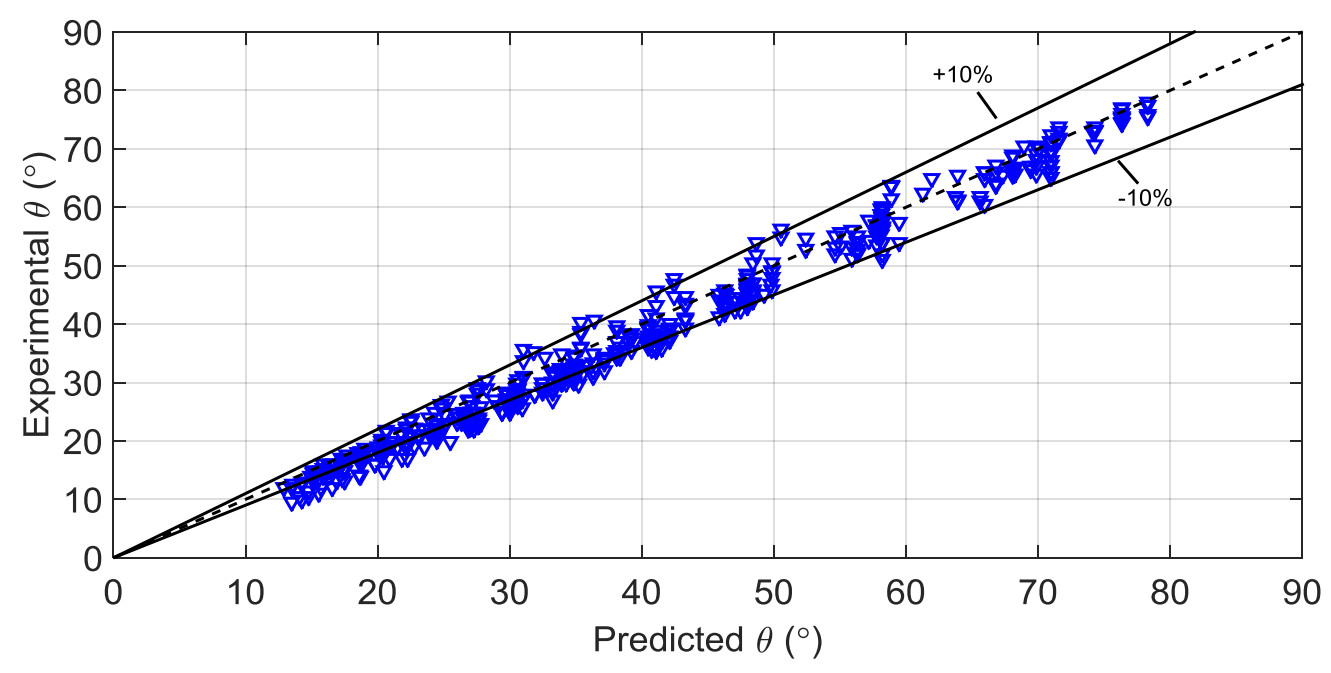

Fig. 10 Equilibrium inclination angles for the flexible filaments in Table 1: measurements vs. predictions of the Luhar and Nepf (2011) theoretical model extrapolated to cylindrical flexible filaments in Eq. (14).

As can be seen in Fig. 10, the agreement between measurements and predictions is quite good (mean absolute error of $8.6 \%$ ). This suggests that the theoretically derived ratio of the Cauchy to buoyancy dimensionless number $\mathrm{Ca} / \mathrm{B}$ indeed captures the relevant physics of flexible reconfiguring structures exposed to steady fluid load, irrespective of their cross-sectional geometry. It can be noted that Eq. (14) overpredicts the inclination angle in the low-angle range. It could be argued that at these highly deflected configurations the filament rigidity may have a nonnegligible effect on the net bending moment. However, as shown before, in the range of Cauchy numbers here studied $\left(7.6 \times 10^{4} \leq \mathrm{Ca} \leq 1.4 \times 10^{7}\right)$ the contribution of the filament bending rigidity is at least 3 orders of magnitude smaller than the weight component. Thus, we suspect that this disagreement might be 
attributed to peculiarities in the flow field which affect the fluid force acting on the inclined body but which are not taken into account in the theoretical formulation, such as flow separation and end-effects. A practical disadvantage of Eq. (14) is that it is implicit in the equilibrium inclination angle. Equilibrium inclination angles measured for the flexible filaments in Table 1 are presented in Fig. 11 as function of the Cauchy to buoyancy ratio $\mathrm{Ca} / \mathrm{B}$.

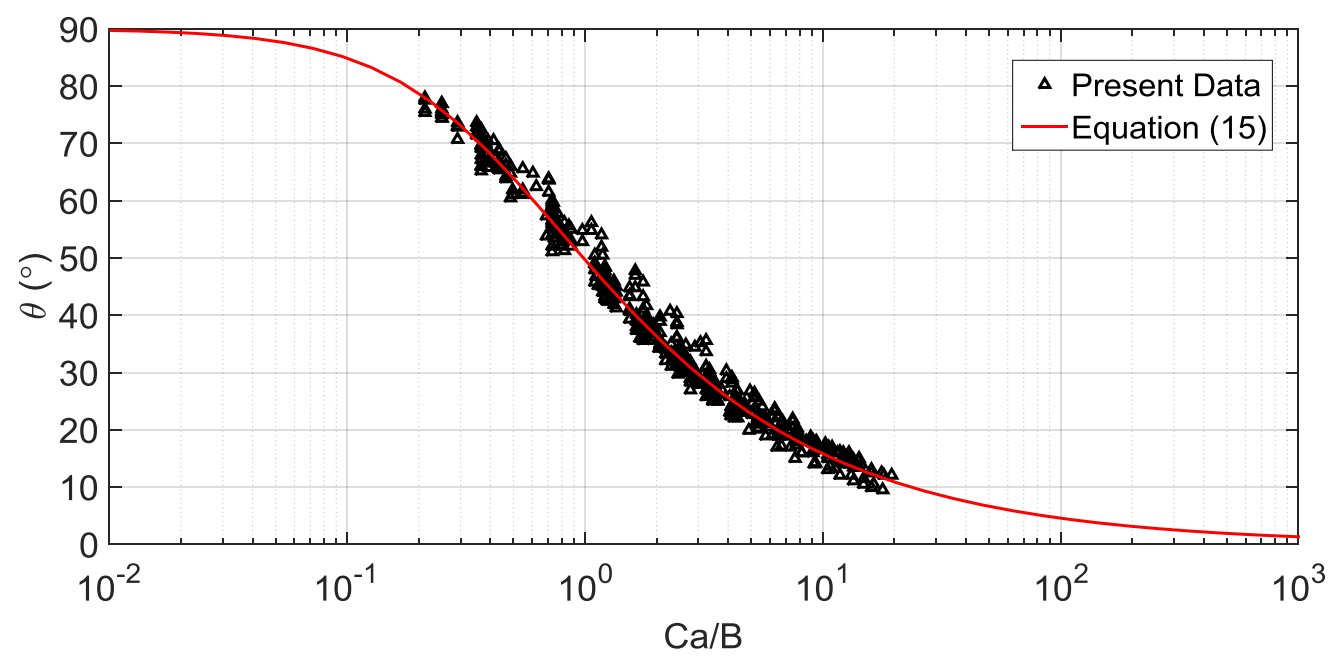

Fig. 11 Equilibrium inclination angles for the flexible filaments in Table 1 vs. Cauchy to buoyancy ratio $\mathrm{Ca} / \mathrm{B}$.

As can be seen in Fig. 11, the data cluster quite well, showing that an empirical correlation between the equilibrium inclination angle and the Cauchy to buoyancy ratio $\mathrm{Ca} / \mathrm{B}$ can provide an explicit alternative to the implicit theoretical model in Eq. (14). In particular, the data in Fig. 11 exhibit an S-shape trend that can be conveniently reproduced with a generalized sigmoid function as follows:

$$
\theta=90 /\left(1+1.20(C a / B)^{1.33}\right)^{0.407}
$$

Equation (15) fits the equilibrium inclination angles for the flexible filaments in Table 1 with a mean absolute error of $5 \%$, thus providing an accurate and explicit empirical alternative to the implicit theoretical model in Eq. (14). It is clear at this point that the Cauchy to buoyancy ratio $\mathrm{Ca} / \mathrm{B}$ encapsulates the relevant physics of flexible reconfiguring structures exposed to steady fluid load. It seems spontaneous, therefore, to try using it to correlate normal force ratios as done in Fig. 12, where the normal force ratio $F_{N} / F_{\perp}$ measured for the filaments in Table 1 is plotted as function of the Cauchy to buoyancy ratio $\mathrm{Ca} / \mathrm{B}$. 


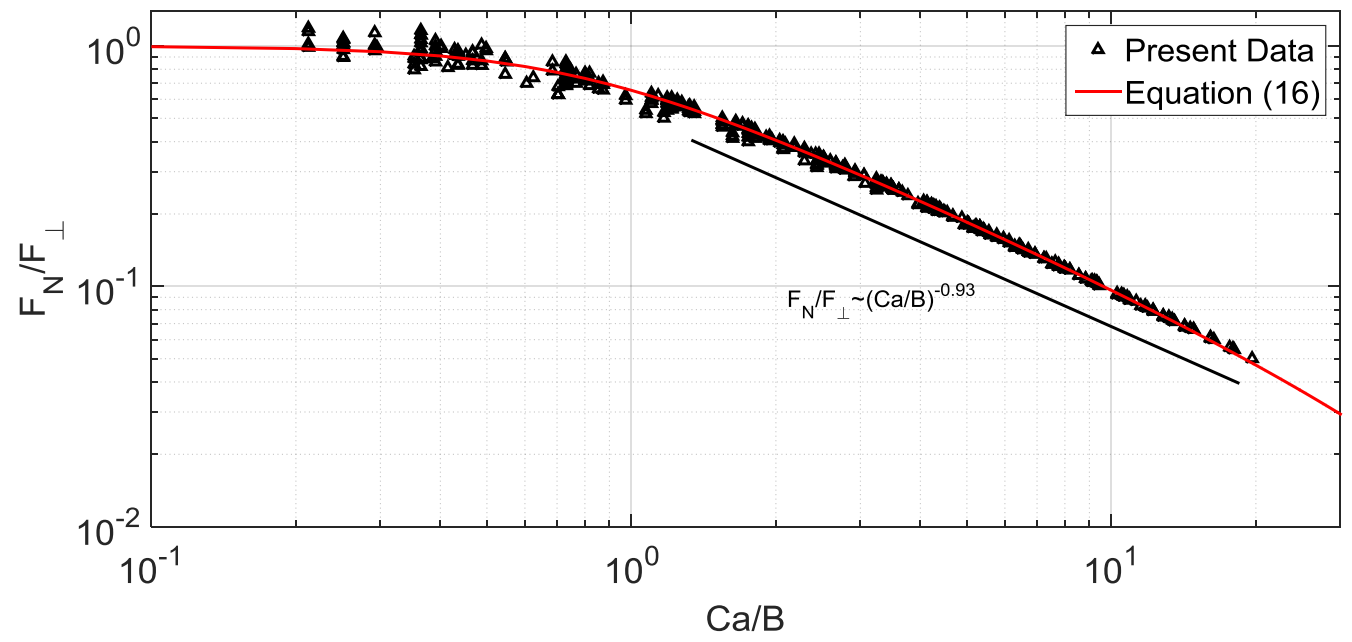

Fig. 12 Normal force ratio measured for the filaments in Table 1 vs. Cauchy to buoyancy ratio $\mathrm{Ca} / \mathrm{B}$.

As can be seen, the data points cluster remarkably well, showing saturation at low Cauchy to buoyancy ratio (where the normal force ratio approaches 1) and a decreasing trend as the Cauchy to buoyancy ratio increases. A simple empirical relation that fits the data in Fig. 12 is provided below:

$$
F_{N} / F_{\perp}=e^{-0.0119(C a / B)}\left(1+1.77(C a / B)^{2.14}\right)^{-0.404}
$$

Measured normal force ratios are compared in Fig. 13 with the predictions of Eq. (16): as can be seen, the agreement between data and predictions is quite good (mean absolute error of $2.9 \%$ ). Equation (16), therefore, can be suggested as a physically-based empirical correlation to predict the normal force ratio in reconfigured flexible filaments in steady fluid flow, which within the limits of the present study is more accurate than the loading function or independence principle previously discussed. 


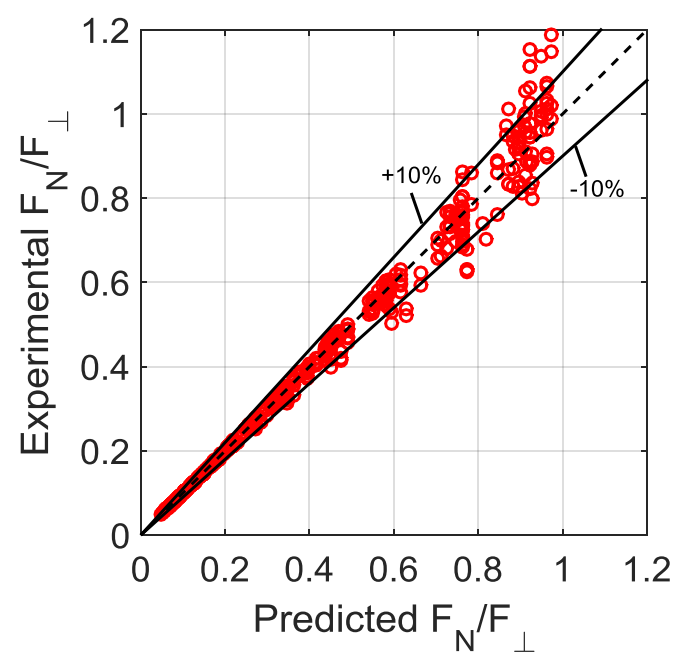

Fig. 13 Normal force ratio for the flexible filaments in Table 1: measurements vs. predictions of Eq. (16).

\section{Concluding remarks}

We described a novel non-invasive experimental technique for measuring the steady normal fluid force on inclined cylindrical bodies by means of the optical analysis of the reconfiguration of flexible filaments exposed to steady fluid flow. During the tests, the Reynolds number varied between 25 and 460, while the buoyancy number and Cauchy number ranges covered were $3.6 \times 10^{4} \leq B \leq 2.1 \times$ $10^{6}$ and $7.6 \times 10^{4} \leq \mathrm{Ca} \leq 1.4 \times 10^{7}$. This indirect technique allows circumventing the difficulty of directly measuring the very small fluid forces (on the order of 10$100 \mu \mathrm{N}$ ) that are at play at the low Reynolds numbers of interest for drag reduction and energy harvesting applications. Particularly, the technique was used here to generate new normal force data for Reynolds numbers between 25 and 460, a range not covered in previous studies. Using these newly generated data we assessed and extended the validity of the loading function and the independence principle approaches for predicting the normal force ratio at low Reynolds number. Our data suggest that the Cauchy to buoyancy dimensionless ratio $\mathrm{Ca} / \mathrm{B}$ originally derived by Luhar and Nepf (2011) for flexible vegetation captures the relevant physics of reconfiguring flexible structures exposed to steady fluid load, and we developed new simple and explicit empirical prediction methods for the equilibrium inclination angle and the normal force ratio that can be suggested for use in general applications with flexible reconfiguring filaments. 


\section{Acknowledgements}

Jorge Silva wishes to thank the National Government of the Republic of Ecuador for funding provided through a scholarship by SENESCYT.

\section{References}

Blevins, R.D., 1990. Flow-induced vibration. Van Nostrand Reinhold Co., Inc., New York, NY (USA).

Bursnall, W.J., Loftin, L.K., 1951. Experimental Investigation of the Pressure Distribution About a Yawed Circular Cylinder in the Critical Reynolds Number Range, National Aeronautics and Space Administration Washington D.C., NACA-TN-24.

Casarella, M.J., Parsons, M., 1970. Cable systems under hydrodynamic loading. Mar. Technol. Soc. J. 4, 27-44.

de Langre, E., 2008. Effects of Wind on Plants. Annu. Rev. Fluid Mech. 40, 141168. doi:10.1146/annurev.fluid.40.111406.102135

Delany, N.K., Sorensen, N.E., 1953. Low-Speed Drag of Cylinders of Various Shapes. Natl. Advis. Comm. Aeronaut. TN-3038.

Ersdal, S., Faltinsen, O.M., 2006. Normal forces on cylinders in near-axial flow. J. Fluids Struct. 22, 1057-1077. doi:10.1016/j.jfluidstructs.2006.05.003

Fage, A., 1930. Drag of Circular Cylinders and Spheres, Aeronautical Research Committee, R\&M No. 1370.

Fage, A., Falkner, V.M., 1931. Further Experiments on the Flow Around a Circular Cylinder, Aeronautical Research Committee, R\&M No. 1369.

Fage, A., Warsap, J., 1929. The effects of turbulence and surface roughness on the drag of a circular cylinder, Aeronautical Research Committee, $R \& M$ No.1283.

Favier, J., Dauptain, A., Basso, D., Bottaro, A., 2009. Passive separation control using a self-adaptive hairy coating. J. Fluid Mech. 627, 451. doi:10.1017/S0022112009006119

Finn, R.K., 1953. Determination of the drag on a cylinder at low Reynolds numbers. J. Appl. Phys. 24, 771-773. doi:10.1063/1.1721373

Grouthier, C., Michelin, S., Bourguet, R., Modarres-Sadeghi, Y., de Langre, E., 2014. On the efficiency of energy harvesting using vortex-induced vibrations of cables. J. Fluids Struct. 49, 427-440. doi:10.1016/j.jfluidstructs.2014.05.004 
Hoang, M.C., Laneville, A., Légeron, F., 2015. Experimental study on aerodynamic coefficients of yawed cylinders. J. Fluids Struct. 54, 597-611.

doi:10.1016/j.jfluidstructs.2015.01.002

Humphreys, J.S., 1960. On a circular cylinder in a steady wind at transition Reynolds numbers. J. Fluid Mech. 9, 603-612.

doi:doi:10.1017/S0022112060001341

Lindsey, W.F., 1938. Drag of cylinders of simple shapes, NACA Annual Report 619.

Luhar, M., Nepf, H.M., 2011. Flow-induced reconfiguration of buoyant and flexible aquatic vegetation. Limnol. Oceanogr. 56, 2003-2017.

doi:10.4319/lo.2011.56.6.2003

Niu, J., Hu, D.L., 2011. Drag reduction of a hairy disk. Phys. Fluids 23, 101701. doi:10.1063/1.3639133

Relf, E.F., Powell, C.H., 1917. Tests on Smooth and Stranded Wires Inclined T the Wind Direction, and a Comparison of Results on Stranded Wires in Air and Water., National Advisory Committee for Aeronautics, R\&M No. 307.

Schewe, G., 1983. On the force fluctuations acting on a circular cylinder in crossflow from subcritical up to transcritical Reynolds numbers. J. Fluid Mech. 133, 265. doi:10.1017/S0022112083001913

Schiller, L., Linke, W., 1933. Pressure and frictional resistance of a cylinder at Reynolds numbers 5,000 to 40,000. Natl. Aeronaut. Sp. Adm. Washingt. D.C., NACA-TM-715.

Schouveiler, L., Eloy, C., Le Gal, P., 2005. Flow-induced vibrations of high mass ratio flexible filaments freely hanging in a flow. Phys. Fluids 17, 47104. doi:10.1063/1.1878292

Smith, R.A., Moon, W.T., Kao, T.W., 1972. Experiments on flow about a yawed circular cylinder. J. Basic Eng. 94.4, 771-776.

Stroman, J.C., 1997. Aerodynamic Drag Coefficients of a Variety of Electrical Conductors. MSc Thesis. Texas Tech University. doi:10.1017/CBO9781107415324.004

Tanida, Y., Okajima, a., Watanabe, Y., 1973. Stability of a circular cylinder oscillating in uniform flow or in a wake. J. Fluid Mech. 61, 769. doi:10.1017/S0022112073000935

Thom, A., 1928. The Boundary Layer of the Front Portion of a Cylinder. Aeronaut. Res. Committee, R\&M No. 1176. 
Tritton, D.J., 1959. Experiments on the flow past a circular cylinder at low Reynolds numbers. J. Fluid Mech. 6, 547-567. doi:10.1017/S0022112059000829

Wieselsberger, C., 1922. New Data on the Laws of Fluid Resistance, National Advisory Committee for Aeronautics, TN-84. 


\section{Appendix A}

\section{A.1 Determination of Young modulus (E) and Poisson ratio ( $V$ )}

Filaments of $L=70 \mathrm{~mm}$ were held hanging tightly from top while the other end was free. A small paper basket was attached to the free end via a cotton string (the unitary strain of the filament due to the weight of this basket was about $1 \%$ ). The reference point for measuring the elongation was the point where the basket was attached. This was the initial configuration, i.e. no deformation, after which small weights of known mass were gently added to the basket and the resulting elongation of the filament was recorded after 30 seconds to allow for the filament to fully stretch. The loads were then carefully removed one by one in order to detect any hysteresis effect. The maximum elongation was kept below $30 \%$ in order to avoid any plastic deformation in the filaments tested.

The diameter change due to the axial deformation of the filament was also measured. Two digital cameras were located perpendicular to each other and focused on the mid-section of the hanging filament. Images were taken before and after the small loads were added to the basket. The Poisson ratio was computed via the relationship: $v=-\left(D_{f}-D_{i}\right) / D_{i}$. Where $D_{f}$ and $D_{i}$ are the measured diameters after and before adding a new load. Image processing was carried out using Matlab.

For each load, the axial stress on the filament was determined using a diameter computed through volume conservation, and cross checked with the one computed via the Poisson ratio. The diameter values in the following table are the initial ones before adding any weight. These were previously determined from images taken with a Scanning Electron Microscope (SEM).

Fig. A1 shows plots of the results for each filament diameter. The slope of the linear part of the data on the stress-strain plot represents the Young Modulus. As a reference the manufacturer stated a value of $0.3 \mathrm{MPa}$ as tensile modulus for this silicone. 
a)

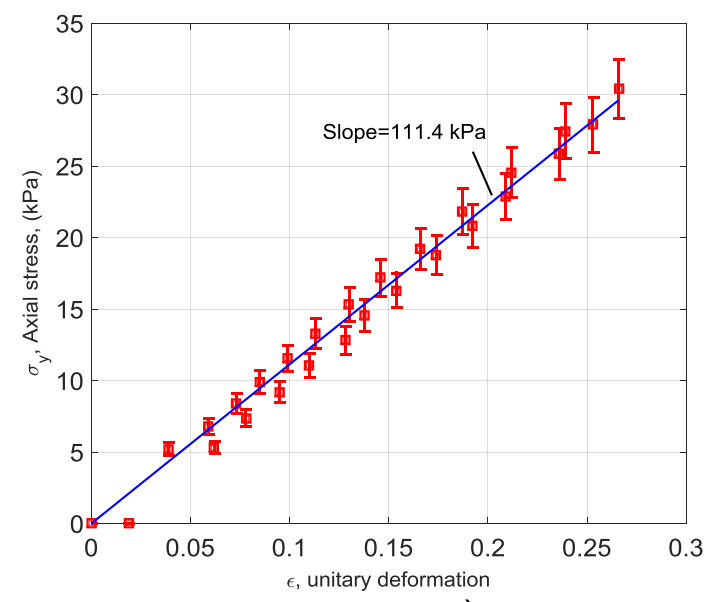

c) b)

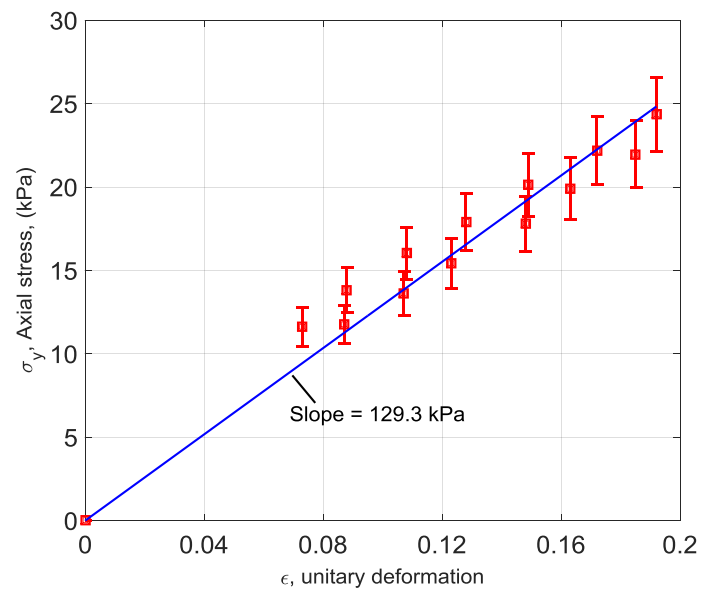

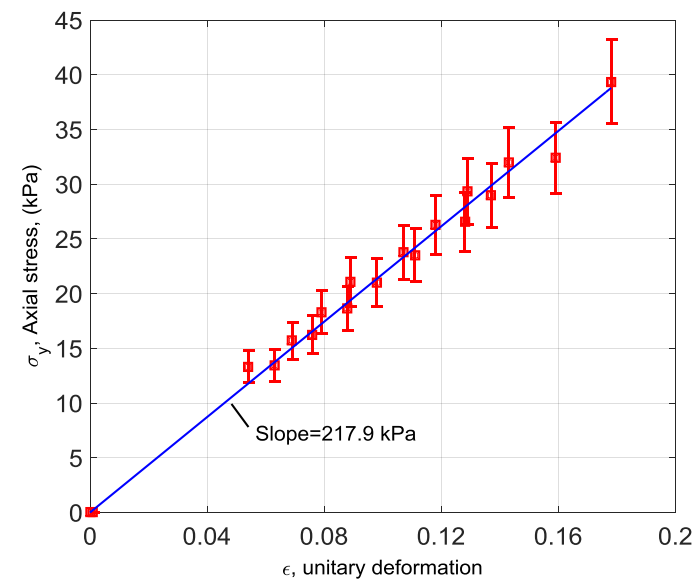

Figure A1. Plots of Axial Stress versus unitary deformation: a) $D=0.66 \mathrm{~mm}$; b) $D=0.46 \mathrm{~mm}$; c) $D=0.40 \mathrm{~mm}$.

Table A1 shows a summary of the results obtained for the Young modulus and the Poisson ratio. These values correspond to the average results from three tests for each filament diameter. The variability of the Young modulus was $10 \%$ on average.

Table A1 Geometry and results from tension tests

\begin{tabular}{ccc}
\hline $\begin{array}{c}\text { Diameter, } \mathbf{D}_{\max } \\
(\mathbf{m m})\end{array}$ & $\begin{array}{c}\text { Young modulus, E } \\
(\mathbf{K P a})\end{array}$ & $\begin{array}{c}\text { Poisson ratio, } \\
\boldsymbol{v}\end{array}$ \\
\hline 0.66 & 115.8 & 0.01 \\
0.46 & 135.5 & 0.01 \\
0.40 & 225.2 & 0.01 \\
\hline
\end{tabular}




\section{A.2 Determination of the Bending rigidity (EI) and torsional spring constant ( $K$ )}

The bending rigidity of the filaments was determined from static deflection tests under self-weight. The filaments were clamped from one end and were let to hang horizontally and bend under their own weight. The filaments initially had a length of $70 \mathrm{~mm}$, and were gradually shortened by carefully cutting pieces of approximately $15 \mathrm{~mm}$. Images of the filaments configuration were taken with a digital camera and were later post-processed using Matlab. The bent configuration of the filaments is due to a balance between the moment due to filament weight and the resistance offered by the bending rigidity $(E I)$ of the structure. The slope variation along the filament was determined from the shape of the filament and the bending rigidity (EI) was subsequently determined from the bending-curvature relationship for beams, i.e. $\frac{M}{E I}=\frac{d \alpha}{d s}$. The local moment $M$ is due to the total weight load perpendicular to the local portion along the filament length s, i.e. $W \cos \alpha$; and $\alpha$ is the local angle as shown in Fig. A2.

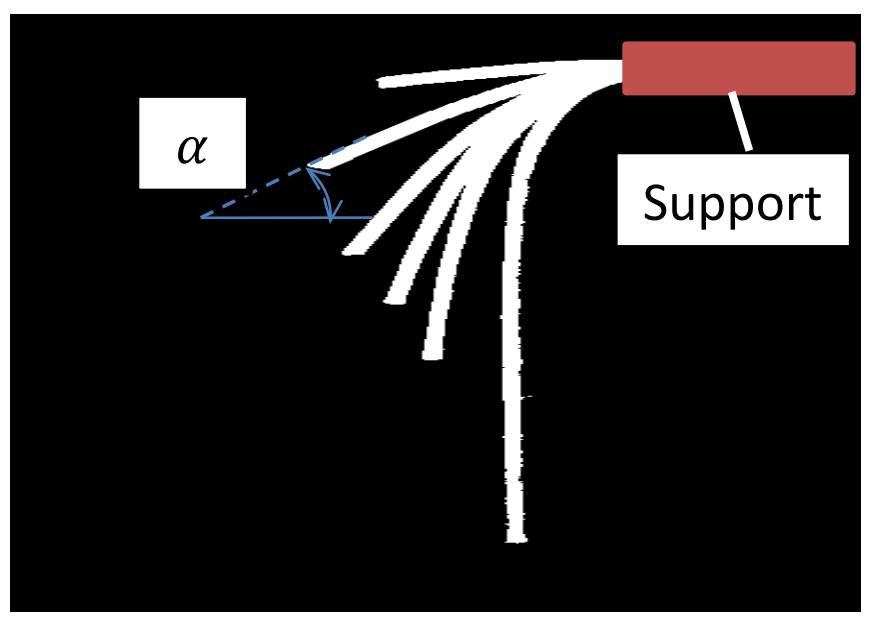

Figure A2 Deflected shapes of a filament under self-weight

The curvature of the filament close to the fixed end, here referred to as a "knee", depends on the moment acting on the axis of the filament. In this particular case, the moment is due to the weight component acting perpendicular to the local curvature. Therefore, this curvature is a characteristic response of the filament due to an external load. This change of curvature due to external load can be modelled as a torsional spring. Therefore, an average characteristic torsional coefficient $(\kappa)$ was determined for representing the moment occurring in this deformed portion of the filament via the following relationship:

$$
\kappa=\frac{M}{\alpha} \approx \frac{W \cos \alpha}{\alpha}
$$


where $\alpha$ is an average of the local angles (in degrees) along the filament. The value of $K$ is the average torsional coefficient, measured in $\mathrm{Nm} /$ degree. Noteworthy, this torsional coefficient was found to be constant for a particular filament diameter, regardless of the filament length. Once this torsional coefficient was determined for each filament, it was used for computing the moment responsible of producing the bend observed during the experiments via $M_{\text {spring }}=$ $\kappa \alpha$, regardless of the nature of the loads producing the deformation. Table A2 shows the results obtained from these tests.

Table A2 Results from average Bending Rigidity and Torsion coefficient

\begin{tabular}{|c|c|c|}
\hline $\begin{array}{c}\text { Diameter, } D_{\text {max }} \\
(\mathbf{m m})\end{array}$ & $\begin{array}{c}\text { Bending Rigidity, EI } \\
\left(\mathrm{Nm}^{2}\right)\end{array}$ & $\begin{array}{c}\text { Torsion coefficient, } \boldsymbol{k} \\
\text { (Nm/deg) }\end{array}$ \\
\hline 0.66 & $1.13 \times 10^{-12}$ & $1.36 \times 10^{-12}$ \\
\hline 0.46 & $3.33 \times 10^{-13}$ & $4.89 \times 10^{-13}$ \\
\hline 0.40 & $2.75 \times 10^{-13}$ & $3.12 \times 10^{-13}$ \\
\hline
\end{tabular}

In this model, the effect of the torsional spring on the equilibrium position of the filament is expected to be minimal since it is proportional to the bending rigidity of the filament, which is very low and may even be neglected. Nevertheless, it was included in the calculations of the normal force. 


\section{Appendix B}

Validation of Constant Temperature Hot-Wire Anemometer Measurements

The straight hot-wire was located $100 \mathrm{~mm}$ downstream of a circular cylinder of diameter $15.5 \mathrm{~mm}$ which was set in cross flow configuration across the wind tunnel test section. The probe was then set $30 \mathrm{~mm}$ offset from the axis of the cylinder to detect vortex shedding. The measurements are presented in Fig. B1, where the cylinder Strouhal number is displayed as function of the cylinder Reynolds number. As can be seen, the measurements compare well with the following well known correlation (Blevins, 1990):

$$
S t=0.198\left(1-\frac{19.7}{R e}\right)
$$

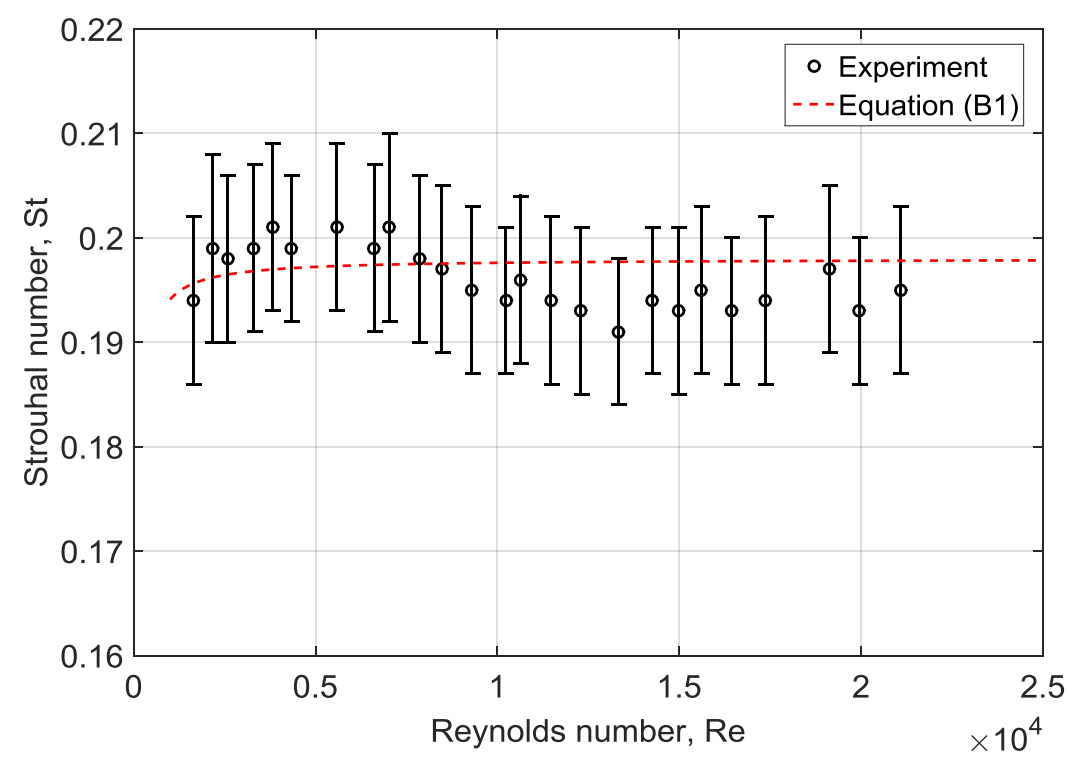

Fig. B1 Test rig validation: Strouhal number vs Reynolds number for a circular cylinder in crossflow. 


\section{Appendix C}
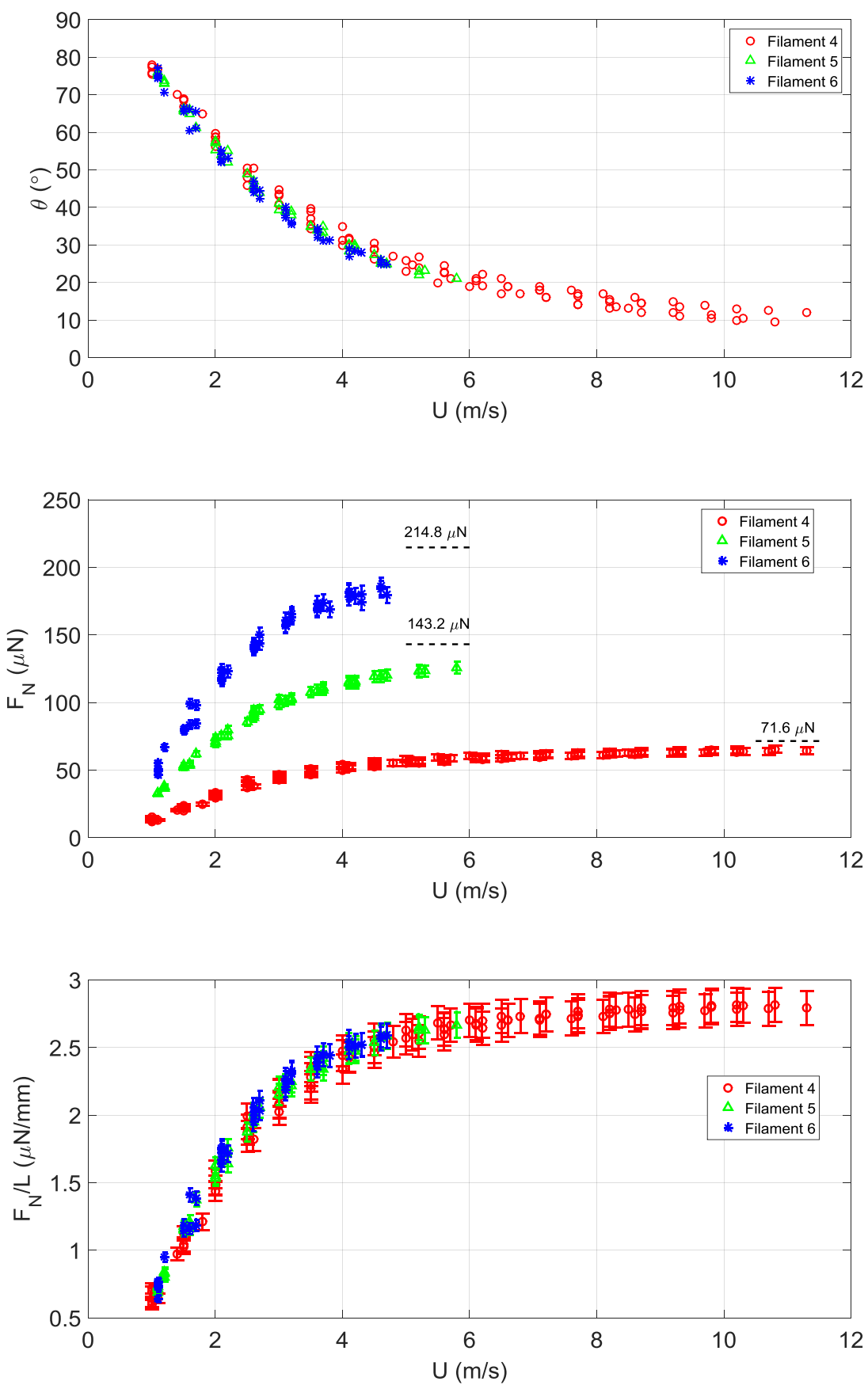

Fig.E1 Results for filaments 4 through 6 from Table 1: Inclination angle vs. flow velocity (top); normal fluid force vs. flow velocity (middle); and specific normal fluid force per unit filament length vs. flow velocity (bottom). 

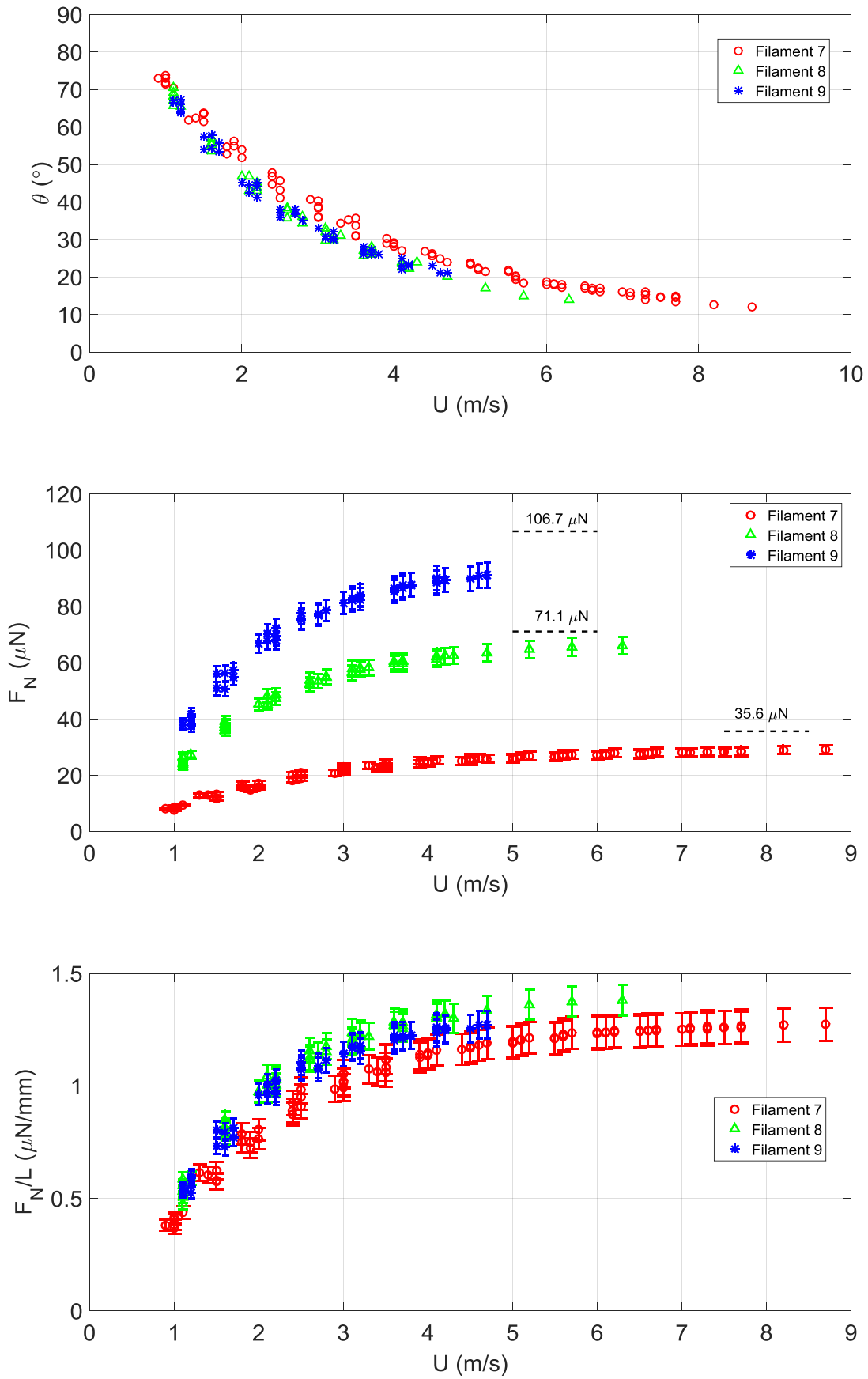

Fig.E2 Results for filaments 7 through 9 from Table 1: Inclination angle vs. flow velocity (top); normal fluid force vs. flow velocity (middle); and specific normal fluid force per unit filament length vs. flow velocity (bottom). 


\section{Appendix D}

The drag coefficient versus Reynolds number correlation for smooth cylinders in cross-flow specifically derived for use here reads as follows:

$$
C_{d}=\left(1.13+\frac{11.4}{R e^{0.808}}\right)^{0.952}
$$

where the numerical coefficients were fitted to a large databank for cylinders in cross flow collected from the literature: 416 data points for smooth circular cylinders in cross flow covering Reynolds numbers between 0.1 to 300,000 , collected from the following works: (Bursnall and Loftin, 1951; Delany and Sorensen, 1953; Fage, 1930; Fage and Falkner, 1931; Fage and Warsap, 1929; Finn, 1953; Humphreys, 1960; Lindsey, 1938; Schewe, 1983; Schiller and Linke, 1933; Smith et al., 1972; Stroman, 1997; Tanida et al., 1973; Thom, 1928; Tritton, 1959; Wieselsberger, 1922). This fitted correlation has a Mean Absolute Percentage Error (MAPE) of $6.5 \%$ for $0.1<R e<500 ; 6.7 \%$ for $0.1<R e<1,000$; and, $7.3 \%$ for $0.1<\operatorname{Re}<300,000$. Data and correlation are shown in the figure below. As can be seen, the proposed correlation fits well the data, although it slightly overpredicts the measurements for Reynolds numbers within $10^{3}-10^{4}$. It is worth noting that the available data in this region are rather limited and quite scattered. In principle, a correlation could be fitted to include data from the drag crisis range $\left(R e \geq 3 \times 10^{5}\right)$. However, these were not included because the present study is focused on low Reynolds numbers, and it would also complicate the fitting procedure. 


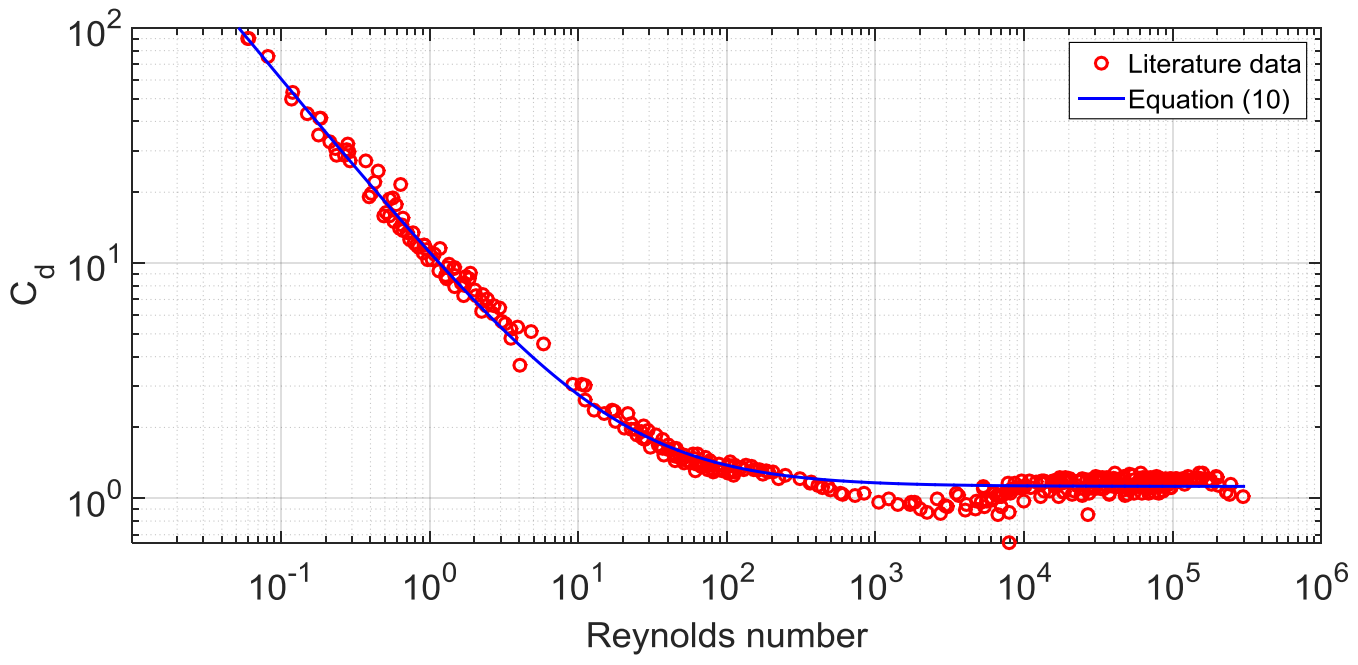

Fig. C1: Data of drag coefficient vs Reynolds number for circular cylinders in cross flow. 


\section{Appendix E}

\section{Literature Experimental Databank for Normal Force on Inclined Cylinders}

We collected data from experimental works in which the authors measured the steady normal fluid force acting on static inclined cylinders (i.e. no vibrations) and with smooth surface finishing. We only considered studies in which the fluid flow was steady and with no open surface effects. Moreover, we focused on studies where only the angle $\boldsymbol{\theta}$ was varied, i.e. no other rotation in other planes. Also, we did not consider data obtained at $R e>3 \times 10^{5}$, i.e. beyond the drag crisis region, because it was not of interest for our application. The main details of the experimental databank collected from the literature are summarized in Table D1.

Table D1: Fluid-dynamics loading experimental databank.

\begin{tabular}{lccccc}
\hline \multicolumn{1}{c}{ Reference } & Fluid & $\boldsymbol{D}(\mathbf{m})$ & $\boldsymbol{R e}^{(\mathrm{a})}$ & $\boldsymbol{\theta}\left(^{\circ}\right)$ & $\begin{array}{c}\text { No. of } \\
\text { points }\end{array}$ \\
\hline $\begin{array}{l}\text { Relf \& Powell, } \\
(1917)\end{array}$ & Air & $9.5 \times 10^{-3}$ & $7.7 \times 10^{3}$ & $0-90$ & 10 \\
\hline $\begin{array}{l}\text { Bursnall and } \\
\text { Loftin, (1951) }\end{array}$ & Air & $5.1 \times 10^{-2}$ & $1.2 \times 10^{5}-3 \times 10^{5}$ & $30-90$ & 17 \\
\hline Smith et al, (1972) & Air & $9.5 \times 10^{-3}$ & $2 \times 10^{3}-1.8 \times 10^{4}$ & $30-90$ & 28 \\
\hline $\begin{array}{l}\text { Ersdal \& } \\
\text { Faltinsen, (2006) }\end{array}$ & Water & $4.8 \times 10^{-2}$ & $\begin{array}{c}2.8 \times 10^{4}- \\
6.4 \times 10^{4}\end{array}$ & $2-18$ & 63 \\
\hline
\end{tabular}

(a) Reynolds number based on cylinder diameter and free-stream velocity

As can be seen in Table D1, all values of the inclination angle from $0^{\circ}$ (axial flow) to $90^{\circ}$ (cross flow) have been investigated, covering a Reynolds numbers range of $2 \times 10^{3}$ to $3 \times 10^{5}$, thus in turbulent flow conditions. Notably, measurements taken close or beyond the drag crisis (i.e. $R e=300,000$ ) are not included in the databank. In particular, available data for yawed smooth cylinders come from (Bursnall and Loftin, 1951; Relf and Powell, 1917; Smith et al., 1972). A recent study was done by (Ersdal and Faltinsen, 2006) in which they measured the normal force on a smooth inclined cylinder at small inclination angles $\left(\theta<20^{\circ}\right)$. In the first case $\operatorname{Re} \sim 7.7 \times 10^{3}$ is based on force measurements; for the second case, data is in the Reynolds number of order $10^{5}$, mostly in the drag crisis range (not included in Table 1); and, finally, for the latter case the Reynolds number is in the orders between $10^{3}$ and $10^{4}$. In the last two cases, the authors only measured pressure drag, not total drag since in these Reynolds number ranges the contribution of pressure drag is predominant compared to frictional drag. 